\title{
Does Top Management Team Heterogeneity Pay?
}

\author{
Patriciah Gachambi Mwangi \\ P.O. Box 64589 \\ 00620 Nairobi \\ Kenya
}

\begin{abstract}
The upper echelons theory argues that the characteristics of the senior managers affect firm performance. This study sought to test this proposition by evaluating the effect of top management team (TMT) heterogeneity on firm performance through a cross sectional descriptive survey. Primary data was collected from 53 large food and beverage manufacturing firms using a structured questionnaire and secondary data relating to the firms' financial performance was obtained from the Kenya Revenue Authority. Using ordinary linear regression, the study established that different heterogeneity components had different effects on the various performance perspectives. Age heterogeneity affected financial and customer performance significantly, education level heterogeneity affected customer and internal processes significantly and tenure heterogeneity affected internal processes performance significantly. On the overall, TMT heterogeneity had a significant negative effect on financial, social and internal processes performance. This confirmed the upper echelons proposition and highlighted the harmful consequences of TMT heterogeneity on performance.
\end{abstract}

Keywords: Top management team heterogeneity, firm performance, upper echelons theory, food and beverage manufacturing firms.

\section{Introduction}

\subsection{Top Management Team Heterogeneity}

The TMT comprises of the managers at the helm of the organization with whom the overall decision making and running of the organization is vested. They are in charge of the entire organization or its major departments. In a bid to derive the most out of the TMT, organizations incorporate managers with a variety of skills (Ancona \& Caldwell, 1992) with the view that the TMT is able to launch superior strategies leading to organization success. TMT heterogeneity means the differences in the attributes and traits of the senior managers of an organization. It implies that the senior management's characteristics are different from one manager to the next. In this case the TMT is made up of managers with a varied attributes. TMT homogeneity on the other hand refers to a situation where the TMT members are alike in their characteristics.

Hambrick and Mason (1984) proposed that organizations mirror their senior managers and thus coalesced the upper echelons theory. They noted that while dealing with strategic choices, managers are influenced a great deal by their behavioural components. Operational decisions are amenable to solutions that can be computed and thus managers have predetermined codes for dealing with them. Strategic decisions on the other hand do not have existing prescriptions and managers have to design appropriate solutions. These decisions therefore reflect the idiosyncrasies of the decision makers as they try to design appropriate solutions for the non routine situations.

Hambrick and Mason (1984) emphasized application of observable managerial attributes as proxies of the managers' values and mental processes. This is because the managers' cognitive bases and values are shaped by their observable characteristics. Based on their characteristics, managers filter and interpret stimuli in a certain way which influences the choices they make. Managers' observable characteristics therefore influence their decisions. They therefore argued that relatively observable manager attributes like age, functional and socioeconomic roots, tenure, education level and financial status could be useful predictors of strategies and performance.

A person's age affects his or her worldview and is a major determinant in a person's behaviour whether implicitly or explicitly. Anecdotal evidence abounds in line with this for instance millennials are more technologically savvy and prefer informal jobs while older people are risk averse and rigid. Empirical evidence is also supportive of this view. Age is associated with more experience, rigidity and resistance to change (Tihanyi, Ellstrand, Daily \& Dalton, 2000). Younger managers are likely to be more open to change and undertake more risky ventures which lead to volatile performance. Herrmann and Datta (2005) noted that age can be a surrogate for a person's experience and their tendency to take risks. 
They observed that managers with advanced ages have less mental and physical endurance and thus less capacity to process information. Age heterogeneity can therefore be associated with strategy variety and reduced consensus which ultimately affect firm performance.

Tenure indicates the duration a manager has been in an organization. Every organization has its own culture and the longer a person spends in the organization, the more he becomes acculturated. Due to this the person's perspective is narrowed as his tenure in the organization increases. Tenure indicates a manager's ability to collect and process information (Herrmann \& Datta, 2005) with long tenure reducing information gathering and processing ability. Wiersema and Bantel (1992) posited that long tenure was linked to a high commitment to status quo and organizational values. Further, people who have been in the organization for long have shared vocabulary and perception of events and good communication (Miller, 1991). Organizations with CEOs with long tenure are likely to have inappropriate structures and strategies mismatched to their environments. Tenure heterogeneity therefore affects a firm's strategic stance and firm performance.

Education level focused on the highest academic qualifications attained by members of the TMT. Education shapes an individual's mental models and information gathering and processing ability. Wiersema and Bantel (1992) asserted that individuals with higher education levels had greater ability to process information and discriminate among different stimuli. Due to this they had a higher ability to tolerate ambiguity, span boundaries and be more innovative. Herrmann and Datta (2005) associated education with mental orientation, willingness to embrace change and knowledge base. However, they noted that higher education could lead to excess analysis. Education heterogeneity avails TMT members with the capacity to seek and analyze opportunities and tolerate ambiguity and thus the ability to launch and sustain aggressive strategies. In addition they can contribute to better firm performance due to well thought out ideas and greater knowledge base.

Functional background also affects the cognitive processes of individuals and their behaviours. In the market place, there exist anecdotal stereotypes based on functional background such as engineers being overly analytical, marketers being frivolous especially with budgets and accountants being mean. A person's functional background shapes their outlook and personality. Wiersema and Bantel (1992) noted that some fields oriented their members towards change than others. Tihanyi et al (2000) observed that certain institutions exposed students to specific way of life which affected their open mindedness. In addition, functional background empowers managers with certain skills and experiences. Mkalama (2014) asserted that functional background reflected a person's depth of relevant knowledge in a specific area which affected the person's effectiveness. A TMT with functional heterogeneity is vested with a larger knowledge base which is crucial for information gathering and sharing which then affects performance.

Gender heterogeneity implies the mix of men and women at the helm of the organization. Gender heterogeneity brings in a variety of personalities and behaviours within the TMT. Dezso and Ross (2012) noted that the presence of female managers in the TMT added the informational and social diversity to the TMT which enriched the behaviour of managers in the organization. Schwab, Werbel, Hofmann and Henriques (2016) demonstrated that managerial groups with either very low or very high gender diversity ended up with group processes which hinder the benefits of moderate diversity. This implies that gender heterogeneity avails the TMT with a capacity to process information and wide perspectives which affects the competitive actions pursued by the organization and the performance. In addition, gender heterogeneity affects the group processes and thus their ability to work together.

\subsection{Firm Performance}

March and Sutton (1997) noted that the interest on firm performance as a dependent variable is most explicit in organization strategy since the field defines it as its primary focus. The field seeks to understand, predict and shape organization performance. Venkatraman and Ramanujam (1996) focusing on the strategic management perspective noted that use of financial indicators of performance was the narrowest conception of firm performance. They suggested that a broader perspective would also emphasize operational measures of performance. This integration of measures is supported by Nourayi and Daroca (1996). Several authors have adopted the balanced scorecard (BSC) in order to incorporate non financial measures such as Mutuku (2012) and Awino (2013). Hubbard (2009) noted that most organizations that adopted the BSC tended to customize it to their own circumstances. In addition, most of the firms had not reached the level of sophistication required to incorporate the BSC in their organizations. Due to this, he proposed the sustainable balanced scorecard (SBSC) which incorporates social and environmental measures in the BSC and adopts measures that can be easily understood by senior managers and is likely to be more accepted by organizations to measure performance. To accommodate this wider perspective of firm performance, this study adopted the SBSC measures. 


\section{Literature Review}

This study was founded on the upper echelons theory which was first described by Hambrick and Mason (1984). The upper echelons theory holds that to fully comprehend organizational actions, it is important to focus on their top managers. They posited that complex decisions largely reflect behavioural factors rather than mechanical considerations. This is because such decisions were limited by many and conflicting goals, several options, different aspiration levels and bounded rationality. Strategic decisions are complex in the sense that they are not amenable to solutions that can be calculated. As such they reflect the decision makers' idiosyncrasies to a large extent. Oppong (2014) opined that the individual attributes of top managers determine how they filtered through the environment which informs their decisions. Therefore to understand organization actions and performance, the biases and dispositions of their top executives must be considered (Hambrick, 2007). Since leadership is shared, the composition of the TMT affects TMT decisions. These propositions laid the foundation for the upper echelons theory, which many scholars have built on.

Dezso and Ross (2012) using 15 years' panel data from Standard \& Poor's firms studied the link between female representation in the TMT and firm performance. They established that female presence in the TMT led to better performance but only if the firm applied innovation strategy. Certo, Lester, Dalton and Dalton (2006) in their metaanalysis of 27 empirical studies established that TMT functional heterogeneity and executive tenure heterogeneity had a significant relationship with performance. However they found no relationship for tenure and education heterogeneity with performance.

Schwab et al (2016) studying data collected for all firms by the Portuguese Ministry of Work and Social Solidarity between 1985 to 2000 established that managerial gender diversity affected performance positively. However when gender diversity approached equivalence in management the positive effect declined. This led to the conclusion that there was a curvilinear relationship between managerial gender diversity and firm performance.

Conversely, some scholars have found the relationship between TMT characteristics and firm performance insignificant. Mkalama (2014) analyzing 96 state corporations in Kenya found out that on the overall TMT demographics had a statistically insignificant effect on performance. Specifically age, education, gender and tenure had no significant influence on performance while functional background had a significant impact. In addition all the demographics affected performance positively.

Mutuku (2012) surveyed 33 commercial banks in Kenya in her study of TMT diversity and firm performance. She determined that there was no significant relationship between diversity in age, gender, tenure in the TMT, academic skills, professional endowment and functional foundations and firm performance. Knight et al (1999) evaluated the intervening influence of group processes on the relationship between TMT variety and strategic consensus based on 76 high technology firms in USA and Ireland. They found out that functional, educational and tenure differences had a significant effect on strategic consensus while age diversity was insignificant. Functional and educational variations had a negative impact on strategic consensus while tenure variety had a positive one.

These findings of a significant relationship between TMT attributes and firm performance are consistent with the upper echelons theory assertions that organizational leadership is a mutual pursuit (Hambrick, 2007). Therefore the joint capabilities, behaviours and TMT exchanges affected strategic behaviour and performance. In addition, TMT heterogeneity helps the TMT in processing of information due to the divergent views that stimulate debate and increased levels of information. Due to the increased ability of the TMT to gather and process information, the firm is able to launch superior strategies which affect performance. However, with the increased diversity is the likelihood for conflict and divisions which are likely to hinder firm performance. This study therefore set out to determine the effect of TMT heterogeneity on firm performance by setting out the following hypothesis.

\section{TMT heterogeneity has no significant effect on firm performance}

\section{Research Methodology}

This study employed a cross sectional descriptive survey design among 53 large food and beverage manufacturing firms in Kenya. This was due to the importance associated with this sector in the macroeconomic growth of the country (KAM, 2016). In addition this study required an established context with firms that are run by TMTs and not lone managers. The food and beverage manufacturing sector had a large number of large firms with established TMTs (Mutunga \& Minja, 2014) appropriate for this study. Primary data relating to the TMT characteristics and non financial performance measures was obtained through a structured questionnaire while secondary data was obtained relating to the financial performance for the 5 year period between 2010 and 2015 was obtained from the Kenya Revenue Authority (KRA). Ordinary linear regression was used to evaluate the independent effects of TMT heterogeneity characteristics on firm performance. 


\section{Results and Discussions}

The study tested the effect of gender, age, tenure in organization, education level and functional background heterogeneities on the six SBSC performance perspectives. Table 1 revealed that there was mixed effects between the TMT heterogeneity components and the performance dimensions. Age heterogeneity had a statistically significant effect on financial performance as evidenced by $p=0.027$ and on customer performance with $\mathrm{P}=0.012$. However, the effect on internal processes, learning and development, social and environmental performance was statistically not significant. Further, age heterogeneity had a negative effect on financial performance but a positive one on customer performance. This was aligned to findings by Tihanyi et al (2000) who noted that the presence of younger managers in the TMT as was the case among the food and beverage manufacturing firms led to volatile performance.

Table 1: Unstandardized Coefficients and p values for TMT Heterogeneity Components and Firm Performance

\begin{tabular}{llllllll}
\hline & & & & Internal & Learning & \& & \\
Predictor & & Financial & Customer & Processes & Development & Social & Environmental \\
\hline \multirow{2}{*}{ Gender heterogeneity } & B & -0.143 & -0.466 & -0.760 & 0.462 & -0.458 & -0.492 \\
& Sig. & 0.661 & 0.402 & 0.148 & 0.356 & 0.525 & 0.488 \\
\hline \multirow{2}{*}{ Tenure heterogeneity } & B & -0.364 & -1.084 & -1.249 & -0.450 & -0.717 & -0.041 \\
\hline \multirow{2}{*}{ Age heterogeneity } & Sig. & 0.261 & 0.052 & 0.017 & 0.363 & 0.317 & 0.953 \\
\hline \multirow{2}{*}{ Education } & B & -2.745 & 5.332 & 2.739 & 1.521 & -1.599 & 1.485 \\
heterogeneity & Sig. & 0.027 & 0.012 & 0.156 & 0.411 & 0.550 & 0.572 \\
\hline \multirow{2}{*}{ Functional background } & B & 0.351 & -1.637 & -1.495 & -0.560 & -1.069 & -1.545 \\
heterogeneity & Sig. & 0.383 & 0.020 & 0.023 & 0.362 & 0.231 & 0.080 \\
\hline \multirow{2}{*}{ TMT Heterogeneity } & Sig. & -0.603 & 1.492 & 2.082 & -1.610 & 0.024 & 0.892 \\
\hline & B & -1.666 & -1.400 & -3.006 & -0.614 & 0.992 & 0.698 \\
\hline
\end{tabular}

Education level heterogeneity had a statistically significant effect on customer performance and internal processes performance as shown by $\mathrm{p}=0.02$ and $\mathrm{p}=0.023$ respectively. However, its effect on financial, learning and development, social and environmental performance was statistically not significant. This partially supported the findings by Mkalama (2014) who found that education had no statistically significant effect on performance. Education level heterogeneity had a negative effect on customer performance and internal processes performance implying that the more the TMT was composed of managers with different education qualifications, the more customer and internal processes performance declined.

Tenure heterogeneity had a statistically significant effect on internal processes with $p=0.017$. However its effect on the other measures of performance namely financial, customer, learning and development, social and environmental performance was statistically not significant which supported findings by Mkalama (2014). The effect of tenure heterogeneity on internal processes was negative indicating that the more the TMT was composed of managers with different tenures in the organization, the more internal processes performance suffered. This contradicted the findings by Certo et al (2006) who found a positive relationship between tenure heterogeneity and financial performance. This could be attributed to contextual and methodological differences since this study applied a cross sectional survey, while the study by Certo et al (2006) was a meta-analysis.

Gender heterogeneity had no statistically significant influence on all the measures of performance. This was consistent with the findings by Mkalama (2014) who established that gender did not affect performance in a statistically significant manner. However, it contradicted the findings by Dezso and Ross (2012) who found that gender disparity in the TMT improves firm's financial performance. Schwab et al (2016) also found a curvilinear relationship between managerial gender variety and firm performance as measured by employee productivity. These differences could be attributed to methodological and contextual differences. These studies were carried out in the USA public companies and Portugal using panel data which is longitudinal in nature while the current study applied cross sectional data in Kenya. Functional background heterogeneity had no statistically significant effect across all the performance measures. This implied that whether there was a variety of managers from different backgrounds or not, firm performance was not affected significantly. Thus the skills and experiences associated with functional backgrounds did not reflect on the firm's outcomes. 
This contradicted the findings by Certo et al (2006) and Mkalama (2014) who found that functional background had a positive effect on performance. The differences in findings could be attributed to the contexts applied by the studies. To determine the overall effect of TMT heterogeneity on firm performance, a composite was developed from the components of TMT. Each of the six performance dimensions was regressed against overall TMT heterogeneity. This study found that TMT heterogeneity affected different dimensions of performance differently. TMT heterogeneity had a statistically significant effect on financial performance. Further, it affected financial performance negatively implying that when the TMT was composed of managers with different characteristics, financial performance declined. This was aligned to the assertions by Knight et al (1999) that although diversity is portrayed as a positive force which results in performance, it is negative since it hinders strategic consensus which affects performance. This contradicted findings by Awino (2013) who found a positive but statistically not significant relationship between TMT diversity and financial performance of commercial banks. This could be attributed to the contextual differences between commercial banks and food and beverage manufacturers.

This study found that TMT heterogeneity had a negative effect on customer performance but this effect was statistically not significant. This was consistent with the findings by Awino (2013) among commercial banks and Kinuu (2014) among firms listed on the Nairobi Securities Exchange. This implied that when performance was measured in terms of the customer perspective of the SBSC, the variety of characteristics in the TMT were not sufficient to affect firm performance.

TMT heterogeneity had a statistically significant effect on internal processes performance. Further, it had a negative effect on internal processes performance. This implied that the more the TMT became heterogeneous the more internal processes performance declined. This was contrary to the findings by Awino (2013) who found the relationship statistically not significant. The relationship between TMT heterogeneity and learning and development performance was negative albeit statistically not significant. This implied that TMT heterogeneity could not account for the variations in learning and development performance. This supported the findings by Awino (2013) among the commercial banks in Kenya.

TMT heterogeneity had a negative effect on social performance which was statistically significant. This implied that TMT heterogeneity was harmful to social performance. This could be attributed to the increased differences among the TMT members which would trigger group dysfunctions (Knight et al, 1999), hindering the TMT from tapping into the potential afforded by the variety of skills and experiences within the TMT. Finally, TMT heterogeneity had a negative but statistically not significant effect on environmental performance. This implied that the effect of TMT heterogeneity alone was not sufficient to affect a firm's environmental performance in a statistically significant manner.

On the overall, this study established that TMT heterogeneity had a significant effect on financial, internal processes and social performance measures but the effect was not significant for customer, learning and development and environmental performance which partially supported the findings by Awino (2013), Muchemi (2013) and Mutuku (2012) who found the relationship not significant. This confirmed the upper echelons propositions that the characteristics of the TMT affect the performance of the organization for some performance measures and therefore the senior executives in an organization matter (Hambrick \& Mason, 1984; Hambrick, 2007). Hambrick (2007) noted that since leadership was a shared activity, the characteristics of the leading coalition would enter into the decision making process and thereby the organization's outcomes. The findings that TMT heterogeneity affected performance therefore provided additional empirical evidence to buttress the upper echelons theory.

It is notable that TMT heterogeneity was found to affect all the measures of performance negatively. TMT heterogeneity bestows wider perspectives, cognitive abilities and capacity to solve problems which results in positive effect on performance as demonstrated by Hambrick et al (1996), Carpenter (2002), Certo et al (2006), Mkalama (2014) and Njagi (2015). However, TMT heterogeneity can also lead to schisms that make it difficult to share information (Ancona \& Caldwell, 1992) and in some cases create outright acrimony and mistrust (Hambrick et al, 1996) thereby becoming a liability to the organization.

This study provided further evidence from the large food and beverage manufacturing firms in Kenya that TMT heterogeneity was detrimental to performance. This was aligned with Knight et al (1999), Hambrick et al (2015) and Yohannes and Ayako (2016) who found that TMT heterogeneity affected performance negatively. This can be explained by increased conflict and divisions among the TMT when heterogeneity increases which hinders the ability of the TMT to work together to deliver on performance. 


\section{Conclusion}

The study revealed that TMT heterogeneity had a significant negative effect on firm performance. In their seminal work, Hambrick and Mason (1984) posited that the attributes of senior managers affected the givens they brought to any decision situation especially when dealing with strategic decisions. They argued that observable manager attributes could be used to predict the organizational strategies and performance. This study concluded that TMT heterogeneity affects firm performance thus confirming the upper echelons proposition. However, the study concluded that this effect was negative and therefore TMT heterogeneity was harmful to firm performance. This implied that as the TMT incorporated managers with a variety of attributes, the managers' ability to work together and deliver on performance declined.

\section{Implications of the Study}

This study was anchored on the upper echelons theory which holds that the attributes of the senior managers can be used to predict the strategies and the outcomes of the firm (Hambrick \& Mason, 1984). The study established that on the overall TMT heterogeneity had a significant effect on firm performance. In addition, Hambrick (2007) noted the need for future research to focus on the process by which TMT characteristics affected performance. This study contributed to this course of research by demonstrating that TMT heterogeneity resulted in fragmentation of the TMT thus adversely affecting performance. This study therefore benefitted future TMT researchers by providing empirical support to the upper echelons propositions as well as the path through which the propositions take.

In addition this study was carried out in the private sector where the policy prescriptions are largely on the prerogative of the organizations themselves. The policies adopted by the organizations are therefore idiosyncratic to the organizations. This study determined that TMT heterogeneity had the potential to harm firm performance. This would help policy makers and practicing managers in attempting to determine optimal levels of heterogeneity in order to avoid negative effects on the performance. This implied that organizations would need to draft policies for recruitment, selection, training and development that would approach TMT heterogeneity cautiously.

\section{References}

Ancona, D.G. \& Caldwell, D.F. (1992). Demography and Design: Predictions of New Product Team Performance. Organization Science. 3(3), 321-341.

Awino, Z.B. (2013). Top Management Team Diversity, Quality Decisions and Organizational Performance in the Service Industry. Journal of Management and Strategy. 4(1), 113-123.

Blau, P. (1977). Inequality and Heterogeneity: A Primitive Theory of Social Structure. New York: Free Press.

Carpenter, M.A. (2002). The implications of strategy and social context for the relationship between top management team heterogeneity and firm performance. Strategic Management Journal, 23(3), 275-284.

Carpenter, M.A., Geletkanycz, M.A. \& Sanders, W. G. (2004). Upper Echelons Research Revisited: Antecedents, Elements and Consequences of Top Management Composition. Journal of Management. 30(6), 749-778.

Certo, S.T., Lester, R.H., Dalton, C.M. \& Dalton, D.R. (2006). Top Management Teams, Strategy and Financial Performance. A Meta-Analytic Examination. Journal of Management Studies. 43(4), 813-839.

Dezso, C.L. \& Ross, D.G. (2012). Does Female Representation in Top Management Improve Firm Performance? A Panel Data Investigation. Strategic Management Journal. 33(9), 1072-1089.

Hambrick, D.C. \& Mason, P.A. (1984). Upper Echelons: The Organization as a Reflection of Its Top Managers. Academy of Management Review. 9(2), 193-206.

Hambrick, D.C. (2007). Upper Echelons Theory: An Update. Academy of Management Review. 32(2), 334-343.

Hambrick, D.C., Cho, T.S. \& Chen, M.J. (1996). The Influence of Top Management Heterogeneity on Firms' Competitive Moves. Administrative Science Quarterly. 41(4), 659-684.

Herrmann, P., \& Datta, D.K. (2005). Relationships between top management team characteristics and international diversification: An empirical investigation. British Journal of Management, 16(1), 69-78.

Hubbard, G. (2009). Measuring Organizational Performance: Beyond the Triple Bottom Line. Business Strategy and the Environment. 18(3), 177-191.

Kenya Association of Manufacturers Directory (2016).

Kinuu, D. (2014). Top Management Team Psychological Characteristics, Institutional Environment, Team Processes and Performance of Companies Listed in Nairobi Securities Exchange (Unpublished Doctoral Thesis). University of Nairobi, Kenya.

Knight, D., Pearce, C.L., Smith, K.G., Olian, J.D., Sims, H.P., Smith, K. A. \& Flood, P. (1999). Top Management Team Diversity, Group Process and Strategic Consensus. Strategic Management Journal. 20(5), 445-465. 
Lubatkin, M.H., Simsek, Z., Ling, Y. \& Veiga, J.F. (2006). Ambidexterity and Performance in Small to Medium Sized Firms: The Pivotal Role of Top Management Team Behavioral Integration. Journal of Management. 32(5), 646-672.

March, J.G. \& Sutton, R.I. (1997). Organizational Performance as a Dependent Variable. Organization Science. 8(6), 698-706.

Miller, D. (1991). Stale in the Saddle: CEO Tenure and the Match between Organization and the Environment. Management Science. 37(1), 34-52.

Mkalama, R.N. (2014). Top Management Team Demographics, Strategic Decision Making, Macro-environment and Performance of Kenyan State Corporations (Unpublished Doctoral Thesis). University of Nairobi, Kenya

Muchemi, A.W. (2013). Top Management Team Diversity and Performance of Commercial Banks (Unpublished Doctoral Thesis). University of Nairobi, Kenya

Mutuku, C.M. (2012). Factors Influencing Relationship between Top Management Team Diversity and Performance of Commercial Banks in Kenya (Unpublished Doctoral Thesis). University of Nairobi, Kenya

Mutunga, S.L. \& Minja, D. (2014). Generic Strategies Employed by Food and Beverage Firms in Kenya and Their Effects on Sustainable Competitive Advantage. International Journal of Business and Management Review. 2(6), 1-15.

Njagi, E.M. (2015). Relationship between Top Management Team Diversity and Performance of Oil Marketing Companies in Kenya (Unpublished MBA Thesis). United States International University.

Nourayi, M.M. \& Daroca, F.P. (1996). Performance Evaluation and Measurement Issues. Journal of Managerial Issues. 8(2), 206-217.

Oppong, S. (2014). Upper echelons theory revisited: The need for a change from causal description to casual explanation. Management: journal of contemporary management issues, 19(2), 169-183.

Schwab, A., Werbel, J.D., Hofmann, H. \& Henriques, P.L. (2016). Managerial Gender Diversity and Firm Performance: An Integration of Different Theoretical Perspectives. Group \& Organization Management. 41(1), 5-31.

Tihanyi, L., Ellstrand, A.E., Daily, C.M. \& Dalton, D.R. (2000). Composition of the Top Management Team and Firm International Diversification. Journal of Management. 26(6), 1157-1177.

Venkatraman, N. \& Ramanujam, V. (1986). Measurement of Business Performance in Strategy Research: A Comparison of Approaches. Academy of Management Review. 11(4), 801-814.

Wiersema, M.F. \& Bantel, K.A. (1992). Top Management Team Demography and Corporate Strategic Change. Academy of Management Journal. 35(1), 91-121.

Yohannes, T.H. \& Ayako, A.B. (2016). Top Management Team Demographic Diversities, Generic Strategy and Firm Performance in Marketing Social Research Association (MSRA) in Kenya. Applied Finance and Accounting. 2(2), 30-45. 